УДК 796.015.2:797.21

DOI https://doi.org/10.26661/2663-5925-2020-1-15

\title{
НАВЧАЛЬНО-ТРЕНУВАЛЬНИЙ ПРОЦЕС ПЛАВЦІВ НА ЕТАПАХ ПІДГОТОВЧОГО ПЕРІОДУ
}

\author{
Крюков Ю. М. \\ кандидат педагогічних наук, \\ професор кафедри теоретичних основ фізичного та адаптивного виховання \\ Класичний приватний університет \\ вул. Жуковського, 70Б, Запоріжжя, Украӥна \\ orsid.org/0000-0003-1886-6382 \\ kryukov051@gmail.com
}

Ванюк Д. В.

кандидат наук із фізичного виховання та спорту, доиент кафедри фізичного виховання

Запорізький національний університет

вул. Жуковського, 66, Запоріжжя, Украӥна

ojrcid.org/0000-0002-6069-074X

vaniuk.daria@znu.edu.ua

Пономарьов В. О.

кандидат наук із фізичного виховання та спорту,

дочент кафедри фізичної культури та спорту

Запорізький національний університет

вул. Жуковського, 66, Запоріжжя, Україна

ojrcid.org/0000-0002-6069-074X

cach02061977@gmail.com

Ключові слова: фізичні вправи, режим дихання, витривалість, адаптація, підготовчий період.
Подано матеріали аналізу різних режимів гіпоксичного тренування, рекомендації фахівців, які вирішують завдання підвищення ефективності тренувального процесу шляхом застосування переривчастих гіпоксичних впливів. Покращення показників функціонального й фізичного стану плавців під час використання (ГТ) відбувається внаслідок адаптації провідних функцій і якостей спортсмена до впливу застосовуваних засобів і методів тренування. Представлені матеріали були використані під час розробки методики застосування гіпоксичного тренування в підготовці плавців на етапах підготовчого періоду. Розроблена методика заснована на принципі доповнення впливу, коли засоби гіпоксичних умов i фізичні навантаження носять рівноспрямований характер. У дослідженнях узяли участь 2 групи плавців (15-17 років, кваліфікація 1 розряд, КМС, МС). У їх підготовці використовувались однакові тренувальні програми. В контрольній групі (n-8) застосовувались традиційні засоби й методи тренування, в експериментальній групі (n-10) традиційні методи тренування доповнювались різними варіантами ГТ. Метою дослідження було обгрунтування впливу режимів гіпоксичного тренування на рівень функціональної та фізичної підготовленості плавців. Зафіксовано, що покращення показників функціонального й фізичного стану плавців у процесі використання гіпоксичного тренування відбувається внаслідок адаптації провідних функцій і якостей спортсмена 
до впливу застосовуваних засобів і методів тренування. У тренуваннях плавців використовувались в основному спрощені способи створення гіпоксичних умов, які не потребують застосування спеціальної апаратури. Переважно застосовувались екстенсивні навантаження на середні, довгі дистанції й короткочасні спринтерські вправи. Тренування в гіпоксичних умовах за одних і тих же характеристик тренувальної роботи викликає значно глибші зміни у внутрішньому середовищі організму спортсменів. Отже, доведено, що цілеспрямоване застосування у тренуванні плавців дихання в умовах помірної гіпоксії й гіперкапнії (ДМП), а також гіповентиляційних режимів дихання безпосередньо зумовило істотне підвищення як швидкісної (анаеробної), так і особливо загальної (аеробної) витривалості.

\title{
EDUCATIONAL AND TRAINING PROCESS OF SWIMMERS AT THE STAGES OF THE PREPARATORY PERIOD
}

\author{
Kryukov Yu. M. \\ Candidate of Pedagogical Sciences, \\ Professor at the Department of Theoretical Foundations of Physical and Adaptive Education \\ Classic Private University \\ Zhukovskogo str., 70B, Zaporizhzhia, Ukraine \\ orsid.org/0000-0003-1886-6382 \\ kryukov051@gmail.com \\ Vaniuk D. V. \\ PhD in Physical Education and Sport, \\ Assistant Professor at the Department of Physical Education \\ Zaporizhzhia National University \\ Zhukovskogo str.,66, Zaporizhzhia, Ukraine \\ orsid.org/0000-0002-6069-074X \\ vaniuk.daria@znu.edu.ua \\ Ponomarov V. O. \\ Ph. D. in Physical Education and Sport, \\ Assistant Professor at the Department of Theory and Methods of Physical Culture \\ Zaporizhzhia National University \\ Zhukovskogo str., 66, Zaporizhzhia, Ukraine \\ orsid.org/0000-0001-7289-1007 \\ cach02061977@gmail.com
}

Key words: physical right, mode of breathing, vitality, adaptation, pre-cooking period.
Materials for the analysis of the maximum regimes of hypoxic trenuvanny, recommendations on the fakhivtsi, the most important part of the effectiveness of the trenuvial process in the process of acquisitiveness of the most frequent troubles. Improvement of the indicators of the functional and physical state of swimmers when using (HT) occurs as a result of adaptation of the leading functions and qualities of an athlete to the effect of the applied means and training methods. The developed technique is based on the principle of complementing the effect, when the means of hypoxic conditions and physical activity are of an equal direction. The aim of the study was to substantiate the influence of hypoxic training modes on the level of functional and physical 
fitness of swimmers. The research involved 2 groups of swimmers, 15-17 years old, qualification -1 category, candidates for master of sports, master of sports. In their preparation, the same training programs were used. In the control group (n-8), traditional means and methods of training were used, in the experimental group (n-10), traditional methods of training were supplemented with various options for HT. Both groups at the start of the experiment were practically the same physical development and level of special training. The performance indicators of the functional and physical swimming pool in the case of the hypoxic trenuvanny exercise in the result of adaptation of the previous functions and the athlete's agility before the entrenchment of the training method. In swimmers, vikorists were taught in the main simplified way to master hypoxic minds, so as not to require the stasis of special equipment. Extensive navigation was midway over the middle, short distance and short sprints right. Trenuvannya in hypoxic minds with the same and quiet characteristics of trenuvalial wiklik robots is significantly greater in the internal environment of the athlete's body. The number of vacancies in trenuvanny swimmers is dying in the minds of the world of hypoxia and hyperacapenia, as well as the seizure in the case of the swimming hypoventilation mode.

Постановка проблеми. Тренувальний процес - це один зі способів досягнення високих результатів, ураховуючи водночас види тренування, етапність підготовки та фізичні якості спортсмена. Невід'ємною частиною тренувального процесу спортсменів, зокрема плавців, є тренувальні вправи, використання яких $€$ тим навантаженням, тим стресовим фактором, який викликає в організмі підвищену активність усіх його функцій. Унаслідок цього в організмі відбуваються адаптаційні зміни. Серед багатьох вправ, які використовуються у програмах тренувальних занять плавців, широко використовуються вправи, що виконуються 3 гіпоксичними варіантами дихання, гіпоксичного тренування (ГТ) $[1 ; 4 ; 6 ; 8]$.

Поліпшення показників функціонального й фізичного стану плавців у процесі використання (ГТ) відбувається внаслідок адаптації провідних функцій і якостей спортсмена до впливу застосовуваних засобів і методів тренування. Тренувальний процес може бути ефективним, якщо є стійкий порядок побудови тренувальних занять i закономірного взаємозв'язку компонентів навантаження один 3 одним протягом усіх періодів підготовки спортсмена $[1 ; 3 ; 4 ; 6 ; 8]$.

Мета, завдання та методи дослідження. Метою дослідження було обгрунтування впливу режимів гіпоксичного тренування на рівень функціональної та фізичної підготовленості плавців. 3 огляду на це нами була розроблена технологічна схема і структура функціональної підготовки кваліфікованих плавців на різних етапах підготовчого періоду тренувального циклу.

У тренуваннях плавців використовувались різні способи створення гіпоксичних умов, які не потребують застосування спеціальної апаратури.
Переважно застосовувались екстенсивні навантаження на середні й довгі дистанції (до 3000 м), 3 одного боку аеробної спрямованості; $з$ іншого короткочасні спринтерські вправи. Додатково у тренуванні використовувалось плавання 3 довільною гіповентиляцією, що досягається шляхом зміни співвідношення рухових і дихальних циклів (один вдих на три, п'ять і сім гребкових рухів). Дихання в умовах помірної гіпоксії й гіперкапнії, які забезпечуються шляхом уведення додаткового «мертвого» простору (ДМП - застосовувалась дихальна трубка для швидкісних видів підводного плавання) $[1 ; 2 ; 5 ; 6 ; 8]$.

Розроблена методика заснована на принципі доповнення впливу, коли засоби гіпоксичних умов i фізичні навантаження носять рівноспрямований характер. Унаслідок диференційованого планування й реалізації тренувальної роботи на різних етапах підготовчого періоду, а також цілеспрямованого застосування додаткових ергогенічних засобів передбачалось отримати більш істотний приріст фізичної працездатності й підвищення компонентів функціональної підготовленості. 3 метою з'ясування ефективності використання різних варіантів (ГТ) на етапах підготовчого періоду запланований порівняльний педагогічний експеримент.

У дослідженнях узяли участь 2 групи плавців (15-17 років, кваліфікація - 1 розряд, КМС, MC). У їх підготовці використовувались однакові тренувальні програми. В контрольній групі (n-8) застосовувались традиційні засоби й методи тренування, в експериментальній групі (n-10) - традиційні методи тренування доповнювались різними варіантами ГТ. Обидві групи на початок експерименту були практично однакового фізичного розвитку й рівня спеціальної підготовки. 
Виклад основного матеріалу. Педагогічний експеримент проводився в 3 етапи, відповідно до етапів підготовчого періоду плавців.

На початку і в кінці кожного етапу експерименту всі його учасники обстежувались за єдиною програмою.

На першому, загальнопідготовчому, етапі (5 тижнів) підготовчого періоду основним завданням було підвищення загального функціонального потенціалу, аеробної продуктивності й рівня фізичної працездатності, тобто параметрів і властивостей організму, котрі визначають функціональну потужність, що стояла перед тренувальним процесом на загальнопідготовчому етапі, підготовчого періоду. Завдання було повною мірою вирішено в обох групах.

Так, життєва ємкість легень, рівень фізичної працездатності, максимальна аеробна продуктивність і показники силових можливостей під час плавання зросли в експериментальній групі відповідно на 7,3; 7,9; 5,9 і 6,3\% (P <0,05). Водночас ці показники в контрольній групі збільшились відповідно всього на 3,5; 4,9; 3,6 і 3,4\% (P <0,05).

В експериментальній групі виявився вагомішим і приріст фізичної працездатності у специфічному плавальному тесті PWCv. Збільшення становило $3,9 \%(\mathrm{P}<0,05)$. У контрольній групі цей показник також зріс, але лише на 2,3\% (Р> 0,05).

В експериментальній групі більш істотно зросли й показники у плавальних тестах, які відображають аеробні можливості організму. Приріст результатів у тестах $10 x 50$ м і 800 м відповідно становив 5,8 і 7,8\% (P <0,05). У контрольній групі результати в цих тестах також збільшились, але меншою мірою, відповідно на $3,9 \%(\mathrm{P}<0,05)$ i $3,8 \%(\mathrm{P}>0,05)$.

Більш істотно підвищився в експериментальній групі й результат у тесті 400 м (на $5,9 \%, \mathrm{P}<0,05)$. У контрольній групі збільшення результату в цьому тесті становило всього $3,2 \%(\mathrm{P}>0,05)$.

Приріст результатів у всіх інших тестах і функціональних пробах знаходився в межах $0,7-3,9 \%$ й був порівнянний в експериментальній і контрольній групах. Необхідно зазначити, що як підсумок організаційної модернізації тренувальних дій у плавців експериментальної групи більш суттєво зріс результат на основній дистанції на 2,7\% $(\mathrm{P}<0,05)$, порівняно $з$ контрольною, в якій збільшення становило всього $1,0 \%(\mathrm{P}>0,05)$.

На другому, спеціально-підготовчому, етапі (5 тижнів) підготовчого періоду 3'ясовувалась ефективність експериментальної програми цілеспрямованого підвищення функціональної мобілізації у плавців.

На цьому етапі передусім як основний ергогенічний засіб застосовувалось дихання через додатковий «мертвий» простір (ДМП). Крім того, на самому початку цього етапу передбачалось застосування й дихальних вправ гіпоксичного характеру.

Унаслідок цього всі показники, котрі відображають рівень функціональної мобілізації, в експериментальній групі зросли більш істотно, ніж у контрольній. Так, середній результат у тесті $2 \times 50$ м в експериментальній групі зріс на $3,0 \%$ $(\mathrm{P}<0,05)$, тоді як у контрольній - на $1,4 \%(\mathrm{P}>0,05)$. Результати подолання контрольних дистанцій у 100, 200 й 400 м плавці експериментальної групи поліпшили відповідно на 2,5; 3,0 і 3,3\% (P <0,05). У контрольній групі це поліпшення відобразилось відповідно в 1,7\% (Р> 0,05); 2,6 і 2,5\% ( $<<0,05)$.

Рівень силових можливостей в експериментальній групі підвищився на 4,4\% (P <0,05), а в контрольній - на 1,8\% (P> 0,05).

На третьому, передзмагальному, етапі (2 тижні) підготовчого періоду спільним завданням для обох груп стало підвищення швидкісних можливостей. Із цією метою, крім звичайних плавальних навантажень відповідної спрямованості, планувалось систематичне застосування ергогенічних засобів, які створюють умови гіперкапнії й гіпоксії: дихання через додатковий «мертвий» простір (ДМП) й гіповентиляційний режим дихання.

Iз представлених даних можна бачити, що завдання розвитку швидкісних можливостей у плавців успішно вирішена в обох групах, що виразилось у підвищенні фізичних і функціональних кондицій плавців.

Водночас в експериментальній групі цей приріст виявився досить істотним у всіх тестах, які відображають швидкісні можливості і швидкісну витривалість. Результати в тестах 50 м, 100 м, 200 м i середній час у тестах 75 м і 2 х50 м в експериментальній групі покращився відповідно на 4,5\%; $4,1 \% ; 3,2 \% ; 3,5 \%$ i $3,2 \%(\mathrm{P}<0,05)$.

У контрольній групі приріст результатів у цих тестах був дещо менший і становив відповідно $2,9 \% ; 2,3 \% ; 3,0 \% ; 2,0 \%$ i $2,6 \%(\mathrm{P}<0,05)$.

Підвищення гіпоксичної стійкості значною мірою зумовило зростання швидкості (анаеробної) й загальної (аеробної) витривалості, відповідно на $3,5 \%(\mathrm{P}<0,05)$ i $2,5 \%(\mathrm{P}>0,05)$.

У підсумку це привело до більш істотного зростання спортивного результату на основних дистанціях у плавців експериментальної групи на $2,8 \%$ ( $<<0,05)$, порівняно 3 контрольною, де це збільшення становило $1,9 \%$ (P $<0,05)$.

Висновки. Отже, цілеспрямоване застосування у тренуванні плавців дихання в умовах помірної гіпоксії й гіперкапнії (ДМП), а також застосування у процесі плавання гіповентиляційних режимів дихання безпосередньо зумовило істотне підвищення швидкісної витривалості (анаеробної), а особливо загальної (аеробної) витривалості. 


\section{ЛITЕРАТУРА}

1. Булгакова Н.Ж. Эффективность применения плавания с задержкой дыхания в тренировке пловцов. Москва : Теория и практика физической культуры, № 7, 1967. С. 8-10.

2. Ганзей С.С., Викулов А.Д., Солопов И.Д. Функциональная подготовка юных пловцов в подготовительном периоде. Ярославский педагогический вестник. Ярославль, 2009. С. 14.

3. Дьяченко А.Ю., Лысенко Е.Н., Виноградов В.Е. Функциональное обеспечение специальной выносливости в циклических видах спорта (на материале академической гребли). Киев. Наука в олимпийском спорте. № 3, 2014. 19 с.

4. Камова Э.И. Влияние интервальной гипоксической тренировки на работоспособность пловцов-ветеранов. Электронный журнал Камского государственного института физической культуры. Pеr. Эл № ФС77-27б59 от 26 марта 2007. 18 с.

5. Кучкин С.Н. Резервы дыхательной системы (обзор и состояние проблемы). Волгоград : 1999. C. 7-51.

6. Солопов И.Н. Произвольный контроль дыхания в тренировочной и соревновательной деятельности пловцов. Волгоград : ВГАФК, 2000. 32 с.

7. Уильямс М. Эргогенные средства в системе спортивной подготовки. Киев : Олимпийская литература, 1997. 255 с.

\section{REFERENCES}

1. Bulgakova N.Zh. (1967) Effektivnost' primeneniya plavaniya s zaderzhkoy dykhaniya v trenirovke plovtsov [The effectiveness of the use of swimming with a breath holding in the training of swimmers]. Moscow : Theory and practice of physical culture. No. 7. P. 8-10.

2. Ganzey S.S., Vikulov A.D., Solopov I.D. (2009) Funktsional'naya podgotovka yunykh plovtsov v podgotovitel'nom periode. [Functional training of young swimmers in the preparatory period]. Yaroslavl Pedagogical Bulletin. Yaroslavl. C. 14.

3. D'yachenko A., Lysenko Ye., Vinogradov V. (2014) Funktsional'noye obespecheniye spetsial'noy vynoslivosti $\mathrm{v}$ tsiklicheskikh vidakh sporta (na materiale akademicheskoy grebli). [Functional support of special endurance in cyclic sports (based on rowing)]. Kiev. Science in Olympic sport. No. 3. 19 p.

4. Kamova E.I. (2007) Vliyaniye interval'noy gipoksicheskoy trenirovki na rabotosposobnost' plovtsov-veteranov [Influence of interval hypoxic training on the performance of veteran swimmers]. Electronic journal of the Kama State Institute of Physical Culture. Per. El No. FS77-27b59 dated March 26. 18 p.

5. Kuchkin S.N. (1999) Rezervy dykhatel'noy sistemy (obzor i sostoyaniye problemy) [Respiratory system reserves (overview and status of the problem)]. Volgograd. S. 7-51.

6. Solopov I. N. (2000) Proizvol'nyy kontrol' dykhaniya v trenirovochnoy i sorevnovatel'noy deyatel'nosti plovtsov [Voluntary breath control in training and competitive activity of swimmers]. Volgograd : VGAFK. $32 \mathrm{p}$.

7. Uil'yams M. (1997) Ergogennyye sredstva v sisteme sportivnoy podgotovki [Ergogenic means in the system of sports training]. Kiev : Olympic Literature. 255 p. 